\title{
Congenital Syphilis Masquerading as Leukemia
}

\author{
Tiffany Lee, MD ${ }^{1,2}$ Stephanie Bell, PAS 3 Jason Scimeme, MD ${ }^{2,4}$ Nizar Maraqa, MD ${ }^{2,5}$
}

${ }^{1}$ Department of Pediatrics, University of Florida College of MedicineJacksonville, Jacksonville, Florida

2 Wolfson Children's Hospital, Jacksonville, Florida

${ }^{3}$ Rocky Mountain College Master of Physician Assistant Studies Program, Billings, Montana

${ }^{4}$ Division of Pediatric Critical Care, University of Florida College of Medicine- Jacksonville, Jacksonville, Florida

${ }^{5}$ Division of Pediatric Infectious Diseases and Immunology, University of Florida College of Medicine- Jacksonville, Jacksonville, Florida

Am J Perinatol Rep 2017;7:e167-e170.
Address for correspondence Nizar Maraqa, MD, Division of Pediatric Infectious Diseases and Immunology, University of Florida College of Medicine-Jacksonville, 653-1 West 8th Street, LRC-3, Pediatrics, L-13, Jacksonville, FL 32209 (e-mail: nizar.maraqa@jax.ufl.edu).

\author{
Abstract \\ Keywords \\ - congenital syphilis \\ - leukemia \\ - leukoerythroblastic \\ anemia \\ - maternal syphilis
}

As of late, the incidence of congenital syphilis in the United States is increasing. Each new case represents a failure of preventing, diagnosing, and treating syphilis in pregnant women. Pediatricians should confirm that all women have received adequate screening for and management of syphilis during pregnancy. Congenital syphilis is easily treatable but may be a diagnostic challenge with high morbidity and mortality.
A common misconception in modern medicine is the notion that congenital syphilis is a disease of the past; that the terms "snuffles" and "Hutchinson's triad" are merely words we read in textbooks. On the contrary, after years of steady decline in reported cases, recent data from the United States have shown that the prevalence of this disease is again on the rise. ${ }^{1,2}$ The resurgence of congenital syphilis in the United States represents a failure of our current health care practices to identify and manage untreated maternal syphilis cases. Every new case of congenital syphilis represents a system failure that would have otherwise been easily prevented. Infants with congenital syphilis may be asymptomatic at birth or present with a variety of early or late manifestations that can prove to be a diagnostic challenge to pediatricians. We report a case of a 5-week-old infant, whose mother received routine prenatal care, who presented with unusual manifestations of congenital syphilis.

\section{Case Study}

A 5-week-old male was brought by his parents to the emergency department (ED) with a 1-day history of progressive "gasping for air." He had been born at 37 weeks' gestation after an uncomplicated pregnancy. Before presen- tation, the parents reported that the infant had breastfed well and had normal urine and stool output. The mother also reported that 2 weeks prior, the infant developed a red, patchy rash on his right foot that spread centrally to cover his entire body eventually. The rash waxed and waned over 2 weeks and had lessened by the time he presented to our facility. Upon questioning, the mother reported adequate prenatal care and denied complications or infections during pregnancy or delivery.

In the $\mathrm{ED}$, the infant had hypothermia $\left(36.2^{\circ} \mathrm{C}\right)$, a respiratory rate of 33 breaths per minute (though deep inspiration was noted), normal heart rate of 114 beats per minute, and a normotensive blood pressure of $81 / 63 \mathrm{~mm} \mathrm{Hg}$. Birth weight was $3,300 \mathrm{~g}$ (between 25th and 50th percentile), height was $53 \mathrm{~cm}$ (90th percentile) while head circumference was not documented. Upon admission, the weight had increased by $720 \mathrm{~g}$ to $4,020 \mathrm{~g}$, and the head circumference was $36 \mathrm{~cm}$ (10th percentile). Physical examination revealed an inactive, frail-appearing infant with significant pallor and dry mucous membranes. He had grunting with intermittent gasping. There were diffuse salmon-colored patches that did not blanch and could be felt deep into the subcutaneous tissue. The lesions were around his mouth and on his extremities and trunk. There was poor peripheral perfusion received

January 4, 2017 accepted after revision May 4, 2017
DOI https://doi.org/

10.1055/s-0037-1603955. ISSN 2157-6998.
Copyright $\odot 2017$ by Thieme Medical Publishers, Inc., 333 Seventh Avenue, New York, NY 10001, USA. Tel: +1(212) 584-4662.
License terms

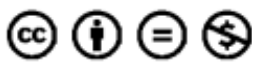


but no cardiac murmurs appreciated. There was splenomegaly with minimal hepatomegaly. The infant had a normal tone with no focal neurological deficits.

Initial laboratory workup revealed severe metabolic acidosis with profound anemia, thrombocytopenia, leukemoid reaction, and electrolyte abnormalities (-Table $\mathbf{1}$ ). A chest radiograph showed no acute cardiopulmonary disease. Abdominal ultrasound demonstrated hepatosplenomegaly. Blood, sputum, and urine cultures were obtained while a lumbar puncture was deferred until the second day of hospitalization due to thrombocytopenia and coagulopathy.

The infant was admitted to the pediatric intensive care unit with a working diagnosis of severe leucoerythroblastic anemia, suspicious of leukemia. He was emergently intubated with the placement of arterial and central venous catheters. He was transfused with packed red blood cells and platelets while correcting his electrolytes and acid/base status. Empiric antibiotics were initiated. Flow cytometry, peripheral blood smear, and bone marrow aspirates were all negative for malignancy. Also, autoimmune hemolytic anemia was ruled out by a negative Coombs test. The pediatric infectious diseases service became involved due to suspicion of congenital infection and concerns for sepsis. A comprehensive review of maternal prenatal laboratories revealed a maternal rapid plasma reagin (RPR) performed at the time of delivery that was reactive at a titer of $1: 128$ (normal: nonreactive). The mother was not aware of this positive result, nor had she been treated during pregnancy or after delivery. She also denied history of syphilis and had a nonreactive RPR during her previous pregnancy 5 years earlier. The infant was immediately started on intravenous (IV) aqueous penicillin G (50,000 units/kg every 4 hours). He was found to have a reactive RPR titer of $1: 128$ and a positive IgM fluorescent treponemal antibody absorption test (normal: nonreactive). Cerebrospinal fluid (CSF) findings were: VDRL positive (normal: negative), white blood cells (WBC) 74/ $\mathrm{LL}$ (normal: $0-30 / \mu \mathrm{L}$ ), protein $570 \mathrm{mg} / \mathrm{dL}$ (normal: $12-60$ $\mathrm{mg} / \mathrm{dL}$ ), and glucose $59 \mathrm{mg} / \mathrm{dL}$ (normal: $45-75 \mathrm{mg} / \mathrm{dL}$ ). An ophthalmologic examination, long bone radiographs, and cranial ultrasonography were normal. Additional infectious workup was unrevealing (-Table 2 ). The infant was weaned off sedation and extubated on the second hospital day. He completed an uneventful 14-day course of IV penicillin. Upon discharge, his hemoglobin was $9.6 \mathrm{~g} / \mathrm{dL}$, and his platelet count was $227 \mathrm{~K} / \mu \mathrm{L}$. In the infectious diseases clinic, 6 weeks after discharge, he was asymptomatic with a normal physical examination. He had a WBC count of $9.31 \mathrm{~K} / \mu \mathrm{L}$, hemoglobin of $9.3 \mathrm{~g} / \mathrm{dL}$, platelet count of $276 \mathrm{~K} / \mu \mathrm{L}$, reticulocyte count of $2.5 \%$, alanine aminotransferase of $27 \mathrm{IU} / \mathrm{L}$, and an RPR titer of 1:64 (i.e., a twofold decrease from pretreatment titer). His long-term neurodevelopmental outcome remains uncertain; however, follow-up at the age of 6 months revealed normal growth and development. He had a normal CSF profile, including a negative CSF VDRL, and a further drop of his RPR titer to 1:16 (an eightfold drop from pretreatment titer). Future follow-up to repeat his RPR test is planned.

The patient's mother and father both received treatment for syphilis with adequate clinical and laboratory response.
Table 1 Initial laboratory test results

\begin{tabular}{|c|c|c|}
\hline Test & Result & Normal range \\
\hline \multicolumn{3}{|l|}{ Complete blood count } \\
\hline White blood cells & $53.7 \mathrm{~K} / \mu \mathrm{L}$ & $5-19.5$ \\
\hline Neutrophils, \% & 23 & $15-35$ \\
\hline Lymphocytes, \% & 65 & $41-71$ \\
\hline Monocytes, \% & 7 & $3-15$ \\
\hline Band neutrophils, \% & 1 & $0-10$ \\
\hline Blasts, \% & 1 & $0-0$ \\
\hline Myelocytes, \% & \multirow[t]{3}{*}{1 (each) } & \multirow[t]{3}{*}{$0-0$} \\
\hline Promyelocytes, \% & & \\
\hline Metamyelocytes, \% & & \\
\hline Hemoglobin & $1.9 \mathrm{~g} / \mathrm{dL}$ & $9-18$ \\
\hline Hematocrit & $6.7 \%$ & $28-55$ \\
\hline Platelet Count & $7 \mathrm{~K} / \mu \mathrm{L}$ & $150-450$ \\
\hline \multicolumn{3}{|l|}{ Coagulation studies } \\
\hline Protime & $21.7 \mathrm{~s}$ & $11.8-15$ \\
\hline INR & 1.9 & \\
\hline Prothrombin time & $34.9 \mathrm{~s}$ & $22.9-37.8$ \\
\hline Fibrinogen level & $145 \mathrm{mg} / \mathrm{dL}$ & $215-485$ \\
\hline D-dimer quantitative & $1.74 \mu \mathrm{g} / \mathrm{mL}$ & $<0.5$ \\
\hline \multicolumn{3}{|l|}{ Blood chemistry } \\
\hline Sodium & $125 \mathrm{mEq} / \mathrm{L}$ & $130-145$ \\
\hline Potassium & $2.9 \mathrm{mEq} / \mathrm{L}$ & $3.4-6.6$ \\
\hline Chloride & $95 \mathrm{mEq} / \mathrm{L}$ & $98-110$ \\
\hline Carbon dioxide & $8 \mathrm{mEq} / \mathrm{L}$ & $20-27$ \\
\hline Glucose & $57 \mathrm{mg} / \mathrm{dL}$ & $45-100$ \\
\hline Blood urea nitrogen & $15 \mathrm{mg} / \mathrm{dL}$ & $3-19$ \\
\hline Creatinine & $0.27 \mathrm{mg} / \mathrm{dL}$ & $0.20-0.80$ \\
\hline Total bilirubin & $2.3 \mathrm{mg} / \mathrm{dL}$ & $0.3-1.8$ \\
\hline Protein & $3.7 \mathrm{~g} / \mathrm{dL}$ & $4.4-6.8$ \\
\hline Albumin & $1.2 \mathrm{~g} / \mathrm{dL}$ & $2.7-4.7$ \\
\hline Calcium & $8.2 \mathrm{mg} / \mathrm{dL}$ & $8.5-11.2$ \\
\hline Magnesium & $2.0 \mathrm{mg} / \mathrm{dL}$ & $1.6-2.5$ \\
\hline Phosphorus & $2.1 \mathrm{mg} / \mathrm{dL}$ & $3.7-7.0$ \\
\hline $\begin{array}{l}\text { Aspartate } \\
\text { aminotransferase }\end{array}$ & $72 \mathrm{IU} / \mathrm{L}$ & $10-60$ \\
\hline $\begin{array}{l}\text { Alanine } \\
\text { aminotransferase }\end{array}$ & $26 \mathrm{IU} / \mathrm{L}$ & $17-63$ \\
\hline Alkaline phosphatase & $348 \mathrm{IU} / \mathrm{L}$ & $67-391$ \\
\hline Lactate dehydrogenase & $387 \mathrm{IU} / \mathrm{L}$ & $150-300$ \\
\hline Uric acid & $4.3 \mathrm{mg} / \mathrm{dL}$ & $2-8.1$ \\
\hline \multicolumn{3}{|l|}{ Blood gases } \\
\hline Arterial pH & 7.28 & $7.35-7.45$ \\
\hline Arterial $\mathrm{PCO}_{2}$ & $14.7 \mathrm{~mm} \mathrm{Hg}$ & $35-45$ \\
\hline Arterial $\mathrm{Po}_{2}$ & 165 mm Hg & $80-110$ \\
\hline
\end{tabular}


Table 1 (Continued)

\begin{tabular}{|l|l|l|}
\hline Test & Result & Normal range \\
\hline \multicolumn{2}{|l|}{ Complete blood count } \\
\hline Arterial $\mathrm{HCO}_{3}$ & $7.0 \mathrm{mmol} / \mathrm{L}$ & $22-26$ \\
\hline Arterial base excess & $-18 \mathrm{mmol} / \mathrm{L}$ & -3 to 3 \\
\hline Lactic acid & $16.6 \mathrm{mmol} / \mathrm{L}$ & $0.5-2.2$ \\
\hline
\end{tabular}

Table 2 Additional infectious workup

\begin{tabular}{|c|c|c|}
\hline Test & Specimen & Result \\
\hline Epstein-Barr virus PCR & Blood & Undetected \\
\hline $\begin{array}{l}\text { Human } \\
\text { immunodeficiency } \\
\text { virus }\end{array}$ & Blood & Undetected \\
\hline Parvovirus B19 PCR & Blood & Undetected \\
\hline Rubella serology & Serum & Negative \\
\hline Cytomegalovirus PCR & Urine & Negative \\
\hline $\begin{array}{l}\text { Respiratory viral PCR } \\
\text { panel for: } \\
\text { - Influenza A } \\
\text { - Influenza B } \\
\text { - Respiratory } \\
\text { syncytial virus } \\
\text { - Adenovirus } \\
\text { - Parainfluenza viruses } \\
\text { - Human } \\
\text { metapneumovirus }\end{array}$ & $\begin{array}{l}\text { Nasopharyngeal } \\
\text { aspirate }\end{array}$ & Negative \\
\hline
\end{tabular}

Abbreviation: PCR, polymerase chain reaction.

\section{Discussion}

The prevalence of congenital syphilis is again on the rise after years of decline, despite well-established preventative techniques, such as maternal screening, and treatment. In 2014, the national rate of congenital syphilis in the United States was 11.6 per 100,000 live births. This had increased from 8.4 in 2012, where it had fallen from 107 in 1991.This dramatic $38 \%$ increase from 2012 to 2014 , not surprisingly, coincided with a $22 \%$ increase in rates of syphilis in women during the same time period. ${ }^{2}$ The Centers for Disease Control and Prevention (CDC) recommends that all pregnant women should be screened for several sexually transmitted infections (STI), including syphilis, at least once during pregnancy, specifically at their very first prenatal visit. ${ }^{3}$ Screening for syphilis should be repeated at the time of delivery and at 28 weeks of gestation in high-risk settings (e.g., a history of STI [particularly human immunodeficiency virus], IV drug use, and homelessness and having multiple partners).

As our case demonstrates, there is significant variation, and unusual ways in which congenital syphilis may present. In fact, syphilis has often been deemed "the great imitator" because of the many possible ways it presents. Of particular importance is differentiating congenital syphilis from leukemias that may affect infants (e.g., congenital leukemia, juvenile myelomonocytic leukemia, or congenital acute lymphoblastic leukemia).
Both entities can present with pallor, lethargy, skin manifestations (syphilitic rash vs. leukemia cutis), hepatosplenomegaly, and a leukemoid reaction. Complete blood count (CBC) findings in congenital syphilis often mirror findings of leukemia (e.g., leukocytosis, anemia, and thrombocytopenia). Several cases of congenital syphilis reported in the literature presented with a $C B C$ picture mimicking malignant disease (e.g., leucoerythroblastic response, or lymphocytosis). ${ }^{4,5}$ Thus, it is not surprising that congenital syphilis is often misdiagnosed as congenital leukemia at first. Fortunately, unlike infants diagnosed with congenital leukemia, congenital syphilis is easily and inexpensively treated.

Congenital syphilis may result in fetal death in up to $40 \%$ of cases, and the case fatality ratio in the United States between 1992 and 1998 was $6.5 \%{ }^{6}$ Fetal infection may occur as early as 9 weeks of gestation with the risk increasing with gestational age. Infection may also occur upon contact with an infectious maternal lesion at the time of birth. Pregnant women newly infected with syphilis may not be aware of symptoms, particularly if their ulcers are painless and on the internal genital tract. Screening of pregnant women remains an essential tool for prevention of congenital syphilis. However, incomplete or absent serologic screening in pregnant women is not uncommon. Close follow-up, and serologic monitoring of mother and fetus are indicated after maternal treatment. However, despite receiving a single-dose penicillin regimen, as many as $14 \%$ of women with secondary syphilis in late pregnancy will still have a fetal death or deliver an infant with congenital syphilis. ${ }^{7}$ All infants born to women with syphilis should be evaluated for congenital infection based on interpretation of paired mother-infant serologic tests and in the context of maternal history (i.e., stage of syphilis, treatment details, and serologic response).

Every new case of congenital syphilis is a demonstration of the Swiss Cheese Model of system failure, in which many mistakes are usually made and missed, resulting in a devastating result for the newborn. In the case of congenital syphilis, the first opportunity for prevention of this outcome occurs with primary prevention of syphilis infection in men and women. The second opportunity occurs with treatment of syphilis upon diagnosis to prevent its morbidity and spread. The third opportunity occurs upon screening for maternal infection during pregnancy. While the fourth opportunity occurs with treatment of said maternal infection during pregnancy to reduce the chance of transmission to the fetus or newborn. A final, yet crucial, opportunity is detection and treatment of congenitally infected newborns by the pediatrician, preferably before discharge from the nursery. Unfortunately for our patient, all these opportunities were missed due to a combination of avoidable human and system errors.

\section{Conclusion}

Congenital syphilis is by no means an extinct entity of the past. It is imperative for pediatricians attending to newborns in the normal nursery to formally confirm the status of maternal syphilis screening before discharge. Also, primary care providers should maintain a high index of clinical 
suspicion and a broad list of differential diagnoses that include congenital syphilis when caring for infants who present with severe anemia or leukocytosis suggestive of leukemia. Our case illustrates the need to increase the efforts to raise public and provider awareness of this ancient, yet ever-present, disease. It also emphasizes the role of vigilant providers in preventing system errors and improving outcomes.

\section{Financial Disclosure}

No honorarium, grant, or another form of payment was given to anyone to produce the article. None of the authors have any potential, perceived, or real conflict of interest.

\section{Author Contribution}

Nizar Maraqa (the corresponding author) wrote the first draft of the article.

\section{References}

1 Centers for Disease Control and Prevention. Syphilis-CDC fact sheet (detailed). Available at: http://www.cdc.gov/std/syphilis/ stdfact-syphilis-detailed.htm. Accessed August 3, 2017

2 Bowen V, Su J, Torrone E, Kidd S, Weinstock H. Increase in incidence of congenital syphilis - United States, 2012-2014. MMWR Morb Mortal Wkly Rep 2015;64(44):1241-1245

3 Workowski KA, Bolan GA; Centers for Disease Control and Prevention. Sexually transmitted diseases treatment guidelines, 2015. MMWR Recomm Rep 2015;64(RR-03):1-137

4 Stevens MC, Darbyshire PJ, Brown SM. Early congenital syphilis and severe haematological disturbance. Arch Dis Child 1987;62 (10):1073-1075

5 Choi JH, Lee HB, Park CW, Lee CH. A case of congenital leukemia cutis. Ann Dermatol 2009;21(01):66-70

6 Gust DA, Levine WC, St Louis ME, Braxton J, Berman SM. Mortality associated with congenital syphilis in the United States, 19921998. Pediatrics 2002;109(05):E79-E9

7 Conover CS, Rend CA, Miller GB Jr, Schmid GP. Congenital syphilis after treatment of maternal syphilis with a penicillin regimen exceeding CDC guidelines. Infect Dis Obstet Gynecol 1998;6(03): $134-137$ 